\title{
AULAS INTERATIVAS NA EDUCAÇÃO À DISTÂNCIA: UM ESTUDO DE CASO NA DISCIPLINA DE MATEMÁTICA E ESTATÍSTICA APLICADA
}

\author{
CURITIBA/PR AGOSTO/2018
}

\author{
Talita Juliana Sabião - UNINTER - talita.s@uninter.com \\ Luciana da Silva Rodrigues - UNINTER - luciana.r@uninter.com \\ Mariana Gonçalves da Silva Frajuca - UNINTER - mariana.s@uninter.com \\ Karoline Walesko - UNINTER - karoline.w@uninter.com
}

Tipo: Relato de Experiência Inovadora (EI)

Categoria: Pesquisa e Avaliação

Setor Educacional: EDUCAÇÃO SUPERIOR

\begin{abstract}
RESUMO
O presente artigo demonstrou por meio de experiência a importância da evolução das ferramentas tecnológicas na EAD como fator essencial para a interação de modo a minimizar o distanciamento físico e incentivar a participação efetiva dos alunos, motivando-os na comunicação coletiva com seus pares e professores para uma aprendizagem significativa e personalizada. A pesquisa desenvolveu-se a partir dos desdobramentos de uma experiência ocorrida em uma IES na disciplina de Matemática e Estatística Aplicada, no início de 2018, onde seu principal objetivo era estimular a participação dos alunos em uma aula ao vivo. Com este estudo, constatou-se através de relatórios que houve um aumento significativo em relação as notas dos alunos nas avaliações demonstrando a importância da inovação da ferramenta no processo pedagógico da IES, resultando significativamente o número de participações dos alunos formando uma rede de interação e construção de conhecimento.
\end{abstract}

Palavras-chave: Educação a distância. Recursos Tecnológicos. Interação. Conhecimento. 


\section{INTRODUÇÃO}

Partimos do ponto de vista de que não podemos negar que a tecnologia e as inovações decorrentes dos seus avanços já são parte do nosso dia a dia, chegamos a um momento decisivo onde as instituições de ensino e professores precisam estar preparados para atender as demandas da nova sociedade denominada como sociedade da informação. No campo da educação esses avanços decorrem, principalmente, do surgimento e uso das tecnologias de informação e comunicação (TIC's) no processo de ensino aprendizagem.

A proposta de ensino a distância no Brasil originou-se como modalidade de ensino, a partir da Lei de Diretrizes e Bases da Educação 9.394/96 (BRASIL, 1996). Na sequência, o Ministério da Educação por meio do decreto lei 5.622 esclareceu as diretrizes gerais da EAD, conforme podemos observar no trecho a seguir:

Art. 10 Para os fins deste Decreto, caracteriza-se a educação a distância como modalidade educacional na qual a mediação didático-pedagógica nos processos de ensino e aprendizagem ocorre com a utilização de meios e tecnologias de informação e comunicação, com estudantes e professores desenvolvendo atividades educativas em lugares ou tempos diversos. (BRASIL, 2005)

Com o advento das Tecnologias de Informação e Comunicação (TIC's) surgiram muitas ferramentas tecnológicas que contribuíram para a construção de um ambiente colaborativo dentro de uma educação que deixou de ser a distância e passou a ser uma educação com vastas possibilidades baseadas na autonomia, pensamento crítico e reflexivo dos alunos.

Segundo Belloni (2009) na EAD a aprendizagem é mediada por novas tecnologias de informação e comunicação e necessitam que as pessoas tenham domínio e habilidades diferentes das requeridas em situações convencionais de aprendizagem. A EAD requer que o sujeito desenvolva competências essências como autogestão, capacidade de resolver problemas, adaptação e flexibilidade diante de novos cenários, responsabilidade, autonomia e proatividade. Essas características fazem da educação a distância uma modalidade educativa mais direcionada a adultos, pois entende-se que são plenamente capazes de auto gerir seus estudos, ou seja, capaz de determinar suas opções e seu próprio processo educativo. Em contrapartida, a necessidade de nos relacionarmos com nossos pares é algo inerente ao ser humano, inclusive, é possível afirmarmos que uma das capacidades que mais se apoiam nas interações é a de aprender. Para Freire (1998) a educação não deve ser compreendida como um processo formal de transmissão de conteúdo, é preciso levar em conta que este processo se fortalece por questões socializantes, que envolvem a emoção e a 
sensibilização dos atores em questão. Nesta mesma perspectiva, Vygotsky (1991) enfatiza que a construção do conhecimento é algo inteiramente social, pois é mediada por meio da linguagem e símbolos dentro de um contexto cultural.

Este estudo justifica-se pela busca crescente da modalidade a distância no âmbito educacional, tornando a EAD uma das principais maneiras de levar educação e conhecimento a um grande percentual da população. E, assim, enquanto profissionais desta modalidade, entendemos a importância do constante aprimoramento dos recursos tecnológicos (AVA) que visam a interação como um fator essencial para minimizar o distanciamento físico e incentivar a participação efetiva dos alunos, motivando-os na comunicação coletiva com seus pares e professores para uma aprendizagem significativa e personalizada.

\section{DESENVOLVIMENTO}

As transformações tecnológicas que têm ocorrido desde as últimas décadas do século $X X$, têm sido muito rápidas, amplas e profundas, onde as pessoas não têm tido tempo suficiente para se apropriar e refletir sobre os seus resultados. Na área educacional, a situação apresenta-se com um agravamento ainda maior, uma vez que muitas instituições de ensino caminham a passos lentos no que se refere a evolução tecnológica, e, nestes ambientes "ultrapassados" temos alunos pertencentes a sociedade digital que vivem conectados, muitas vezes, full time a um mundo muito mais atrativo.

Conforme Kenski (2003, p. 21) o homem transita culturalmente mediado pelas tecnologias que the são contemporâneas. Elas transformam suas maneiras de pensar, sentir, agir. Mudam também suas formas de se comunicar e de adquirir conhecimentos. Para Demo (2015) e Libâneo (2014) o processo de aprendizagem deve ocorrer de forma diferenciada do formato engessado e tradicional, que ainda encontramos em muitos ambientes educativos. Para os autores, a educação deve ser encarada como um processo colaborativo entre alunos e professores, de modo a permitir que todos contribuam com suas experiências para a construção do conhecimento. Hoje, grande parte de nossos alunos participam ativamente da geração digital que apresenta novas possibilidades de aprender e encarar o relacionamento com outros alunos e seus professores (Prensky, 2016).

Integrar o presencial do virtual já faz parte do planejamento de alguns professores. Hoje, encontramos um número considerável de professores que conhecem e exploram metodologias inovadoras apoiadas na utilização de aplicativos e plataformas digitais, 
conectados em rede com seus alunos para a produção do conhecimento. Conforme Viana, Ataíde, Ferreira (2015, p.5) a modalidade de ensino à distância pode ser entendida como uma proposta pedagógica para uma aprendizagem interativa que promova autonomia acadêmica de maneira responsável, crítica e criativa.

De fato, a EAD atingiu uma posição de destaque no cenário educacional, assumindo seu papel como escola virtualizada para um grande percentual da população. Todavia, um dos desafios também da EAD, seria não permitir que a figura do professor fosse vista como agente principal igualando-se ao que chamamos por ensino tradicional, reproduzindo nas salas virtuais uma educação bancária, onde a proposta se resume a simples disponibilização de materiais como um depósito de informação e receptação pelos alunos (Freire, 1987). Ao contrário, para VALENTE (2002), a abordagem na educação a distância do estar junto virtual deve integrar o uso dos vários recursos do ambiente virtual para criar situações de aprendizagem que favoreçam o aluno e sirvam como alicerce para seu conhecimento. Nestas situações de aprendizagem, o aluno pode vivenciar um processo de ação reflexiva, de articulação com a prática, de depuração e de (re)construção do conhecimento.

Ainda na perspectiva de VALENTE (2002):

\footnotetext{
Com isso estabelece-se um ciclo de ações que mantém o aluno no processo de realização de atividades inovadoras, gerando conhecimento sobre como desenvolver essas ações, porém com o suporte do professor. A internet facilita o "estar junto virtual" do professor com o aluno, auxiliando seu processo de construção do conhecimento. Embora esta abordagem permita a implantação de processo de construção de conhecimento via telemática, ela implica mudanças profundas no processo educacional.
}

Sendo assim, na EAD a mediação didático-pedagógica dos processos de ensino e aprendizagem ocorre com a utilização de meios e tecnologias de informação e comunicação, com alunos e professores tutores desenvolvendo atividades educativas em lugares ou tempos diversos. Promovendo a inclusão de alunos que por situações diversas não teriam a disponibilidade para frequentar cursos presenciais.

Como já dito, a incorporação de ferramentas tecnológicas na EAD oportunizou a criação dos Ambientes Virtuais de Aprendizagem (AVA) com recursos voltados para o ambiente educacional possibilitando a organização, o gerenciamento e as várias formas de interação.

\subsection{A EVOLUÇÃO DOS AMBIENTES VIRTUAIS DE APRENDIZAGEM}

\subsubsection{TelEduc}


Em 2001 foi disponibilizado a primeira versão do TelEduc, sendo o primeiro ambiente para EAD como software livre, tanto no cenário nacional quanto internacional. Este fato contribuiu para aumentar o número de instituições públicas e privadas, que passaram a usar esta ferramenta no processo de educação.

O TelEduc é um ambiente de educação a distância que começou a ser desenvolvido em 1997, a partir de uma proposta de dissertação de mestrado do Instituto de Computação da Universidade Estadual de Campinas (UNICAMP). O desenvolvimento deste AVA foi realizado pelos pesquisadores do Instituto de Computação da Unicamp, junto com o Núcleo de Informática Aplicada à Educação (NIED), e sua proposta inicial era a formação continuada dos professores da área de informática .

Os primeiros usuários do TelEduc foram as universidades públicas que utilizavam os materiais dando suporte a comunicação e interação entre os participantes.

\subsubsection{Moodle}

O Moodle é um ambiente virtual de aprendizagem a distância desenvolvido pelo australiano Martin Dougiamas em 1999, formado em Ciências da Computação com Mestrado e Doutorado em Educação focalizados na área de conhecimento sobre a natureza da aprendizagem e colaboração. Este ambiente foi desenvolvido com o propósito que fosse possível a adequação conforme a necessidade do momento. Por ser um ambiente gratuito, ainda é um software bastante utilizado por várias instituições no mundo e possui uma grande quantidade de pessoas contribuindo para a correção dos erros e desenvolvimento de novas ferramentas assim como a discussão sobre metodologias pedagógicas de usabilidade.

\subsubsection{AVA - Ambiente Virtual de Aprendizagem}

Ambientes virtuais de aprendizagem são softwares, normalmente criados pelas instituições de ensino, para o processo de ensino aprendizagem do professor - aluno em cursos oferecidos pela modalidade a distância.

Este ambiente permite a criação de cursos e de suas características, de forma personalizada, bem como a disponibilização dos materiais e ferramentas, ajudando assim os professores- tutores online no gerenciamento dos alunos e acompanhamento de seus progressos mediante ao que está sendo proposto na sala virtual, colaborando assim com o conhecimento, que é programado neste ambiente. 
Esta plataforma de acesso online deve ser dinâmica e utilizar uma linguagem visual clara e objetiva, preocupada com as necessidades e a realidade dos alunos, de forma que ao buscar o que deseja, não encontre dificuldade no acesso. As salas de aprendizagem neste ambiente podem estar divididas por disciplina ou área específica, facilitando assim o acesso e busca do aluno pelo que deseja.

O ambiente virtual de aprendizagem (AVA), permite uma aproximação do aluno com sua instituição, seu curso, coordenador, professor e tutor online, por meio das ferramentas de apoio ao ensino aprendizagem, sejam elas assíncronas ou síncronas.

Nesse processo, cada vez mais o número de ferramentas dentro destas plataformas tem crescido, o aprimoramento e a inovação tem aproximado cada vez mais o aluno com o professor neste método educativo, em algumas destas, as interações acontecem instantaneamente.

Neste caso, são as ferramentas síncronas, aquelas onde é necessário a participação do aluno e professor- tutor online no mesmo momento, de forma virtual, para conclusão ou dúvidas de alguma aula, por exemplo. Podem ser ferramentas síncronas as web conferências, audioconferências, chats.

Já as ferramentas que são desconectadas do tempo real, são chamadas de assíncronas. Neste tipo de ferramenta o aluno tem mais autonomia para estudar no momento em que desejar, dando uma liberdade maior a estudante, sem que ele precise estar conectado com o outro individuo para que a interação aconteça. Podem ser ferramentas assíncronas o fórum, e-mail, roteiros de estudos.

De acordo com Santinello (2015, p.37):

Os AVAs são tecnologias digitais que foram criadas para e-learning (aprendizagem eletrônica) e que oferecem conteúdos a distância, disponibilizando ferramentas online (síncronas e assíncronas) para serem utilizadas por pessoas que porventura naveguem nos ambientes.

Os AVAs estão alocados na internet, devendo-se considerar que a rede permite "a possibilidade não só de buscar informações, como também auxiliar o professor no processo de educação a distância, utilizando novos métodos de interação como o aluno. Como participação em Chats, listas de discussão, e vídeo-conferências." (Moura; Azevedo; Mehlecke, 2005, apud Santinello, 2015).

Em ambientes virtuais, as ferramentas disponíveis são necessárias a produção de conhecimento, onde o aluno encontra todas as oportunidades de aprendizagem, já que 
sua interação com a plataforma deve the fornecer subsídios necessários na avaliações, provas e atividades corriqueiras. Abaixo segue uma breve descrição de algumas ferramentas que podem ser encontradas neste ambiente:

\begin{tabular}{|c|c|}
\hline $\begin{array}{l}\text { ink Tutoria: ferramenta assíncrona, } \\
\text { orém com tempo de resposta o mais } \\
\text { ápido possível ao aluno. Neste campo } \\
\text { aluno insere sua pergunta, e em } \\
\text { eguida a tutoria online procura } \\
\text { esponder de forma rápida e precisa } \\
\text { ua dúvida. Somente membros de } \\
\text { lisciplinas vigentes podem enviar suas } \\
\text { lúvidas para a Tutoria Central. Esta } \\
\text { erramenta aproxima o aluno da central } \\
\text { le atendimento da coordenação e } \\
\text { utoria de seu curso. }\end{array}$ & $\begin{array}{l}\text { Rotas de aprendizagem: é un } \\
\text { ferramenta onde o aluno encontra s } \\
\text { material pertinente à disciplina, slid } \\
\text { das aulas e vídeo aulas, podendo est } \\
\text { fragmentada em páginas e nele est } \\
\text { depositados todos os textos, dicas } \\
\text { leitura como cases e artigos científicc } \\
\text { links de estudos do youtube, reflexõ } \\
\text { sobre os temas. Neste ambiente } \\
\text { aluno é instigado a pesquisar, a troc } \\
\text { ideias, colocar em prática o assun } \\
\text { proposto. }\end{array}$ \\
\hline $\begin{array}{l}\text { Chat: já está ferramenta é síncrona } \\
\text { com data e hora marcada), é um } \\
\text { spaço online de bate papo sobre } \\
\text { lgum assunto, tema, aula. Trata-se de } \\
\text { ma ferramenta interativa, simultânea, } \\
\text { odendo ou não ser mediada por um } \\
\text { rofessor tutor. }\end{array}$ & $\begin{array}{l}\text { Material complementar: serve cor } \\
\text { um complemento da ferramenta cita } \\
\text { acima, aqui são depositados } \\
\text { calendários de apoio ao aluno } \\
\text { materiais extras para auxílio em se } \\
\text { estudos. }\end{array}$ \\
\hline $\begin{array}{l}\text { Rádio web: ferramenta síncrona (com } \\
\text { data e hora marcada), pode-se utilizar } \\
\text { a ferramenta chat (descrita acima) no } \\
\text { mesmo momento, com o intuito de } \\
\text { enriquecer ainda mais o debate que } \\
\text { está acontecendo via áudio, porém } \\
\text { sem contato visual. }\end{array}$ & $\begin{array}{l}\text { Fórum: uma ferramenta assíncrona ( } \\
\text { textos ou imagens são inseridos, } \\
\text { espera de que alguém comece } \\
\text { interação), é um espaço onde } \\
\text { possível propor a discussão } \\
\text { conhecimento adquirido sobre o tem } \\
\text { em grupo, esta deve ser fundamenta } \\
\text { e exemplificada para a troca ideias } \\
\text { experiências. }\end{array}$ \\
\hline
\end{tabular}

Fonte: as autoras, 2018.

As ferramentas, sejam elas assíncronas ou síncronas, estimulam a colaboração dos alunos para a interação e participação, enriquecendo a construção do conhecimento e aprendizado.Fonte: as autoras, 2018 


\subsubsection{Relato de Experiência}

Pensando sempre no processo de melhorias e que realmente evolvessem os alunos com relação a conteúdo e os incentivassem a uma participação nos momentos interacionais, foi criado no Ambiente Virtual de Aprendizagem uma nova maneira de operacionalizar e transmitir as aulas ao vivo.

Esse relato de experiência ocorreu em uma Instituição de ensino superior na disciplina de Matemática e Estatística Aplicada, no início de 2018, e consistiu em uma evolução do número de alunos participando das aulas ao vivo.

Ocorre que nesta instituição as aulas ao vivo são previstas em calendário acadêmico, e ocorrem duas vezes em cada disciplina e tem como objetivo fazer uma retomada de conteúdos de modo prático, o material que é utilizado pelo docente da disciplina fica disponível no Ambiente Virtual de Aprendizagem 48 horas antes da transmissão da aula.

No antigo formato (até o final do ano de 2017) a única maneira de participar das aulas ao vivo (interativas) era comparecendo no polo de apoio presencial e somente de lá que os alunos conseguiam participar da aula e interagir via chat e telefone. Entretanto na grande maioria das aulas ao vivo o número de interações eram pequenas fazendo com que essa aula acabasse tendo um caráter de revisão de conteúdo e não de interação reflexiva. Esta realidade gerou a busca por alternativas que atraísse o aluno a participar.

O que mudou: Foi solicitado a equipe do suporte tecnológico e responsável pelo Ambiente Virtual de Aprendizagem que desenvolvessem um novo campo no AVA em que os alunos conseguissem acessar as aulas ao vivo sem precisar se deslocar até o polo de apoio presencial, de forma em que a transmissão fosse ao vivo e interação síncrona. O acesso é em tempo real e pode ser pelo celular, tablet ou computador.

A solicitação foi atendida e aumentou consideravelmente o número de participações dos alunos, sinalizando o seu efeito viral, que era desejado pela coordenação do curso.

Os posicionamentos ocorridos no momento da aula interativa, tem um caráter complementar a aula já que cada aluno traz o um recorte distinto baseado em sua experiência e percepção dos conteúdos ministrados. Os comentários se pontuaram extremamente ricos trazendo peculiaridades regionais engrandecendo a temática e reflexão. O número de alunos conectados foi tal que muitos dos participantes, no chat, tiveram que ser respondidos posteriormente pela tutoria com apoio do professor da disciplina. 
Deste modo conseguimos grandes resultados, além da facilidade do acesso as aulas ao vivo, acesso em tempo real, efetiva troca de experiências baseadas nas realidades dos alunos o que torna o aprendizado efetivo, por meio da interação não só do professor e aluno, mas entre eles. Estatisticamente, através de relatórios disponíveis no Ambiente Virtual de Aprendizagem, constatou-se que em 2017, 58\% dos alunos alcançaram a média necessária para aprovação acima de 70 , e que em $201871 \%$ dos alunos alcançaram a média acima de 70 no comparativo entre os anos na disciplina de Matemática e Estatística Aplicada. Assim, demonstrando a eficácia e importância da ferramenta no processo de interação e troca de conhecimento entre professor e aluno através da Plataforma.

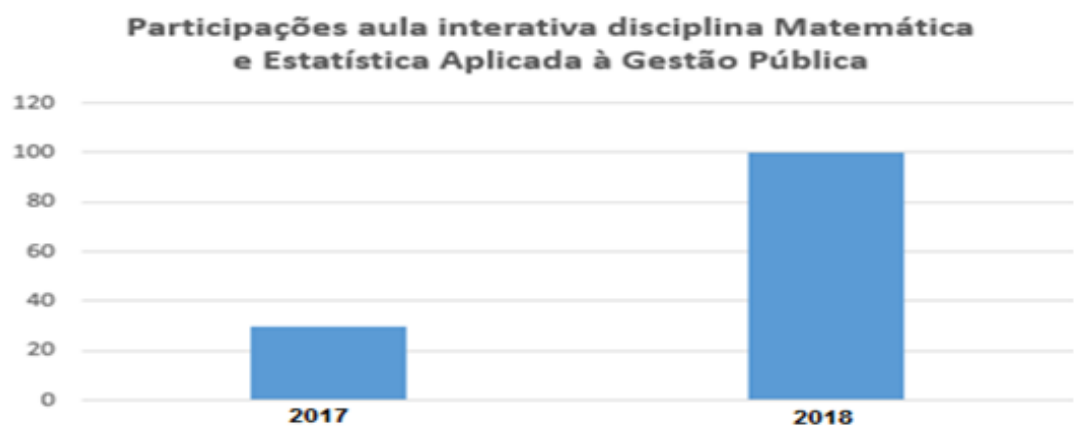

Fonte: Tecnologias Educacionais, 2018.

\section{CONSIDERAÇÕES FINAIS}

Com o avanço das ferramentas tecnológicas, no âmbito social e educacional, é notório que qualquer ferramenta que venha a agregar os interesses dos envolvidos no processo sejam recebidos de forma positiva. Devido a esta mudança na globalização da era digital, as instituições de ensino também tiveram que se aperfeiçoar para caminhar lado a lado com seus parceiros, criando assim ferramentas e suportes necessários para atendê-los.

No presente artigo foi identificada a necessidade de implantação, melhorias e avanços na plataforma do Ambiente Virtual de Aprendizagem, fazendo com que cada vez mais os alunos participem e tenha interação na modalidade EAD. Desta forma, a experiência relatada parte da percepção de que os alunos precisam do acesso em suas mãos, em tempo real e com facilidade de interação. Acredita-se que essa nova ferramenta gerou sentido no que tange à participação e isso motivou um grau de envolvimento maior por parte dos alunos.

\section{REFERÊNCIAS}


Belloni, M. L. Educação a distância, 5.ed. São Paulo: Autores Associados, 2009.

BRASIL. Decreto no 5.622, de 19 de dezembro de 2005. http://www.planalto.gov.br/ccivil_03/_ato2004-2006/2005/decreto/d5622.htm acessado em 20/04/2018

DEMO, Pedro. Aprender como autor. São Paulo: editora Atlas, 2015.

FREIRE, P. Pedagogia da autonomia: saberes necessários à prática educativa. 8. Ed. Rio de Janeiro. Paz e Terra, 1998.

FREIRE, P. Pedagogia do oprimido. 17. Ed. Rio de Janeiro. Paz e Terra, 1987.

KENSKI, Vani Moreira. (2003); Tecnologias e Ensino Presencial e a Distância: Práticas Pedagógicas. São Paulo: Papirus.

LIBÂNEO, J. C. Adeus professor, adeus professora? (Questões de nossa época). São Paulo: editora Cortez, 2014.

SANTINELLO, J. Ensino superior em ambientes virtuais de aprendizagem (AVA): formação docente universitária em construção. Curitiba: Intersaberes.

PRENSKY, M. Education to better their world: unleashing the power of 21st -century kids. N. Y: Teachers College Press, 2016.

VALENTE. J.A. A espiral da aprendizagem e as tecnologias da informação e comunicação: repensando conceitos. São Paulo: casa do psicólogo, 2002.

VIANNA, Luciano José; ATAIDE, Cintia Aparecida; FERREIRA, Marussa Campos. Educação a Distância no Brasil: Cotidiano, Prática, Avanços e Perspectivas. Encontro Internacional de Formação de Professores e Fórum Permanente de Inovação Educacional, v. 8, n. 1, 2015.

VYGOTSKY, L.S. A formação social da mente. 4. Ed. São Paulo, Martins Fontes, 1991. 